\title{
Porphyromonas endodontalis
}

National Cancer Institute

\section{Source}

National Cancer Institute. Porphyromonas endodontalis. NCI Thesaurus. Code C86656.

A species of obligately anaerobic, Gram-negative, rod shaped bacteria assigned to the phylum Bacteroidetes. This species is nonmotile, non-spore forming, indole positive, alpha-fucosidase, trypsin, and catalase negative, liquefies gelatin, produces hydrogen sulfide, utilizes trypticase, proteose, and peptone as energy sources, nonfermenting, pigmented, and does not reduce nitrate or hydrolyze starch or esculin. P. endodontalis is associated with periodontal disease. 